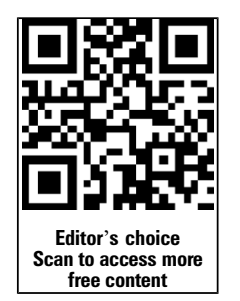

- Additional material is published online only. To view please visit the journal online (http://dx.doi.org/10.1136/ gutjnl-2015-309197)

For numbered affiliations see end of article.

\section{Correspondence to \\ Dr Wei-cheng You, \\ Key Laboratory of \\ Carcinogenesis and \\ Translational Research (Ministry \\ of Education), Department of \\ Cancer Epidemiology, Peking \\ University Cancer Hospital \& Institute, 52 Fu-cheng Road, Hai-dian District, Beijing 100142, P. R. China; weichengyou@yahoo.com}

Dr. Meinhard Classen, Technische Universität München, International Digestive Cancer Alliance, 81675 Munich, Germany; meinhard.classen@|rz.tum.de

K-fP and LZ contributed equally.

Received 15 January 2015 Revised 20 April 2015 Accepted 24 April 2015 Published Online First 18 May 2015

\section{CrossMark}

To cite: Pan K-feng, Zhang L, Gerhard M, et al. Gut 2016;65:9-18.

\title{
A large randomised controlled intervention trial to prevent gastric cancer by eradication of Helicobacter pylori in Linqu County, China: baseline results and factors affecting the eradication
}

\author{
Kai-feng Pan, ${ }^{1}$ Lian Zhang, ${ }^{1}$ Markus Gerhard ${ }^{2}$ Jun-ling Ma, ${ }^{1}$ Wei-dong Liu, ${ }^{3}$ \\ Kurt Ulm, ${ }^{2}$ Jian-xi Wang, ${ }^{3}$ Lei Zhang, ${ }^{1}$ Yang Zhang, ${ }^{1}$ Monther Bajbouj, ${ }^{2}$ \\ Lan-fu Zhang, ${ }^{3}$ Ming Li, ${ }^{3}$ Michael Vieth, ${ }^{4}$ Rui-yong Liu, ${ }^{3}$ Michael Quante, ${ }^{2}$ \\ Le-hua Wang, ${ }^{3}$ Stepan Suchanek, ${ }^{5}$ Tong Zhou, ${ }^{1}$ Wei-xiang Guan, ${ }^{1}$ Roland Schmid, ${ }^{2}$ \\ Meinhard Classen, ${ }^{2,6}$ Wei-cheng You ${ }^{1}$
}

\section{ABSTRACT}

Objective To clarify the full range of benefits and adverse consequences of Helicobacter pylori eradication as a strategy for gastric cancer prevention, the community-based intervention trial was launched in Linqu County, China.

Design A total of 184786 residents aged 25-54 years were enrolled in this trial and received ${ }^{13} \mathrm{C}$-urea breath test. H. pylori positive participants were assigned into two groups, either receiving a 10-day quadruple antiH. pylori treatment or lookalike placebos together with a single dosage of omeprazole and bismuth.

Results The prevalence of $H$. pylori in trial participants was $57.6 \%$. A total of 94101 subjects completed the treatment. The overall $H$. pylori eradication rate was $72.9 \%$ in the active group. Gender, body mass index, history of stomach disease, baseline delta over baselinevalue of ${ }^{13} \mathrm{C}$-urea breath test, missed medication doses, smoking and drinking were independent predictors of eradication failure. The missed doses and high baseline delta over baseline-value were important contributors in men and women (all $P_{\text {trend }}<0.001$ ). However, a doseresponse relationship between failure rate and smoking or drinking index was found in men (all $P_{\text {trend }}<0.001$ ), while high body mass index $\left(P_{\text {trend }}<0.001\right)$ and history of stomach disease were significant predictors in women. The treatment failure rate increased up to $48.8 \%$ (OR $2.87,95 \% \mathrm{Cl} 2.24$ to 3.68 ) in men and $39.4 \%$ (OR $2.67,95 \% \mathrm{Cl} 1.61$ to 4.42 ) in women with multiple factors combined.

Conclusions This large community-based intervention trial to eradicate $H$. pylori is feasible and acceptable. The findings of this trial lead to a distinct evaluation of factors influencing eradication that should be generally considered for future eradication therapies.

Trial registration number ChiCTR-TRC-10000979 in accordance with WHO ICTRP requirements.

\section{INTRODUCTION}

Helicobacter pylori (H. pylori) is a recognised cause of chronic gastritis and peptic ulcer disease, and may play an important role in the etiology of

\section{Significance of this study}

What is already known on this subject?

- Gastric cancer is a global public health burden, nearly one million new cases are diagnosed each year worldwide, of which $42 \%$ cases occur in China.

- Helicobacter pylori infection is the main risk factor for gastric cancer, and it was classified as a class I carcinogen for gastric cancer by International Agency for Research on Cancer in 1994.

- The Shandong Intervention Trial launched in Linqu in 1995 yielded a 39\% reduction in gastric cancer incidence rate after 15 years follow-up.

- Benefits and adverse consequences of strategy for gastric cancer prevention by eradication of H. pylori are still in concern in the community setting.

What are the new findings?

- The large community-based intervention trial to eradicate $H$. pylori is feasible and acceptable in a high-risk area of gastric cancer in China. It gained an elimination of $72.9 \%$ of $H$. pylori in such community intervention trial without severe side effects among all the subjects during the entire 30-month trial period.

- Gender, body mass index, history of stomach disease, baseline delta over baseline-value of ${ }^{13} \mathrm{C}$-urea breath test, missed medication doses, smoking and drinking were independent predictors of eradication failure.

How might it impact on clinical practice in the foreseeable future?

- The findings of this trial lead to a distinct evaluation of the factors influencing eradication of $H$. pylori that should be generally considered for future eradication therapies, particularly in a community-based intervention trial. 
gastric cancer (GC). ${ }^{12}$ The development of GC in a subset of H. pylori-infected individuals may be a result of subtle changes in the gastric epithelial cells induced by bacteria and host inflammatory response, ${ }^{3}$ including DNA alterations and an imbalance between proliferation and apoptosis. ${ }^{4}$ In 1994, the International Agency for Research on Cancer has classified $H$. pylori as a class I carcinogen for GC. ${ }^{6}$ In 2005, the $H$. pylori-GC Task Force recommended that for countries with a high risk of GC, the greatest benefit would be gained by eradicating or preventing $H$. pylori infection in early adulthood. ${ }^{7}$

Linqu County, an underdeveloped rural region in Shandong Province, was identified to be one of the areas with the highest incidence of GC in China. Since 1983, a series of epidemiological investigations have been conducted in this region to explore aetiology and prevention of this common cancer worldwide. ${ }^{8-12}$ Indeed, $50-85 \%$ of children aged $3-10$ years and $67 \%$ of the adults in Linqu were infected by H. pylori, ${ }^{910}$ and H. pylori infection was a risk factor for progression from atrophic gastritis to intestinal metaplasia, dysplasia and GC. ${ }^{11}$

Consequently, we conducted a Shandong Intervention Trial in Linqu in $1995 .^{12} 13$ This trial yielded a $40 \%$ reduction in the prevalence of advanced gastric lesions as well as a favourable effect on GC after 7 years. ${ }^{12}$ Moreover, the trial participants were continually followed for an additional 8 years, showing a $39 \%$ reduction in GC incidence rate even among older subjects and those with advanced baseline pathology. ${ }^{14} 15$ A metaanalysis with a total of 6695 participants including our trial in Linqu also showed that the relative risk for GC was $0.66(95 \%$ CI 0.46 to 0.95 ), suggesting that $H$. pylori eradication is effective in preventing GC. ${ }^{16}$ However, a recent report from the International Agency for Research on Cancer working group on H. pylori revealed concerns about the generalisability of $H$. pylori screening and treatment, and possible adverse consequences of programmes applied in the community setting. ${ }^{17}$

There was a unique opportunity to conduct a large community-based randomised trial in Linqu, which will provide more solid data to evaluate the full range of benefits and adverse consequences of strategy for GC prevention by eradication of $H$. pylori. In addition, this trial can extensively explore the factors affecting eradication that should be considered for future treatment of $H$. pylori, particularly in a community setting. The following text reports our detailed design, baseline results and factors influencing $H$. pylori eradication of this newly initiated community-based randomised trial with 184786 residents in Linqu.

\section{METHODS}

This intervention trial was a collaborative investigation between Peking University Cancer Hospital \& Institute (PUCI), International Digestive Cancer Alliance and Technische Universität München.

\section{Study population}

In March 2011, 347811 residents aged 25-54 years identified from a roster of 980 villages in 10 townships of Linqu were invited to participate in this trial (figure 1). The PUCI staff helped each village chief to distribute a written message to explain the aim and eligibility of the study, and a Brochure of 'Helicobacter pylori Infection and Gastric Cancer and Gastric Lesions' to explain the possibility of risk of $H$. pylori infection to GC and gastric lesions. Informed consent for participation was obtained from each subject; it was explicitly explained that H. pylori positive residents would be assigned into a high dose or a low dose group, and they are free to stop enrolment and leave the study at any time, and have a right to receive any medical care. Residents with the following conditions were excluded: peptic ulcers, serious medical conditions, undergoing active treatment for cancer, currently or previously on antibiotic therapy for $H$. pylori infection, history of congestive heart failure, respiratory failure, stroke, seizures, pregnancy, and mental or psychiatric illness.

A structured questionnaire was used at baseline including items on demographic variables, medical history, family cancer history, stomach disease history (including stomach pain, acid reflux and history of gastritis), occupation, smoking, alcohol drinking and dietary information. All interviews were conducted by trained interviewers using a computerised Data Collection and Management System. We also performed a physical examination in all subjects including measurements of height and body weight. In addition, two 4-mL blood samples were collected from trial participants.

\section{Methodology of ${ }^{13} \mathrm{C}$-urea breath test}

Each subject was requested to swallow a pill containing $75 \mathrm{mg}$ ${ }^{13} \mathrm{C}$-urea (Min.99 atom $\%{ }^{13} \mathrm{C}$, Campro Scientific $\mathrm{GmbH}$, Germany) with $20 \mathrm{ml}$ of water in the morning. Exhaled air was collected in sampling tubes 30 min later. ${ }^{13} \mathrm{CO}_{2}$ values were determined using a gas isotope ratio mass spectrometer, and delta over baseline-value (DOB) was used to express the difference between $30 \mathrm{~min}$ and baseline. The concentration of ${ }^{13} \mathrm{CO}_{2}$ at $30 \mathrm{~min}$ that exceeded the baseline more than 3.8 parts per thousand $(>0.38 \%)$ was regarded as a positive indicator of H. pylori infection.

\section{Data collection and management system}

We developed a data collection and management system, including: (1) Scanning System: scanning participant's ID and printing the individual barcode; (2) Interview System: computerised interviews to collect baseline information; (3) Web-based Data Editing: storing data in a database and integrating it online; and (4) Database Management System: building a database for effective storing and retrieval on demand. Access to the database was limited to authorised researchers of the trial.

\section{Randomisation and blinding}

$H$. pylori positive residents were assigned into two groups using cluster randomisation by village, either receiving high dose therapy (group A) or low dose therapy (group B). H. pylori negative residents were assigned into group $C$ (figure 1). A blocked stratified cluster randomisation scheme in each 10 townships was used. All villages within the township were first ranked by population size in descending order. Double-blinded blocks of six consecutively ranked villages were then identified, and two treatment groups were randomly assigned.

\section{Interventions}

The H. pylori positive subjects received either a 10-day quadruple anti-H. pylori treatment (group A) with omeprazole $20 \mathrm{mg}$ twice daily, tetracycline $750 \mathrm{mg}$ three time a day, metronidazole $400 \mathrm{mg}$ three time a day and bismuth citrate $300 \mathrm{mg}$ twice daily, or lookalike placebos of tetracycline and metronidazole together with single dosages of $20 \mathrm{mg}$ omeprazole and $300 \mathrm{mg}$ bismuth citrate (group B) (see online supplementary table S1).

To reach and maintain a high compliance, all participants took the medications in the house of the village leaders, and PUCI staff monitored the intake of the drugs at 6:00 and 18:00 over the 10-day period. All participants were also required to sign or fingerprint in the medication intake log daily to measure 
Figure 1 Participant flow diagram.

${ }^{13} \mathrm{C}$-UBT, ${ }^{13} \mathrm{C}$-urea breath test.

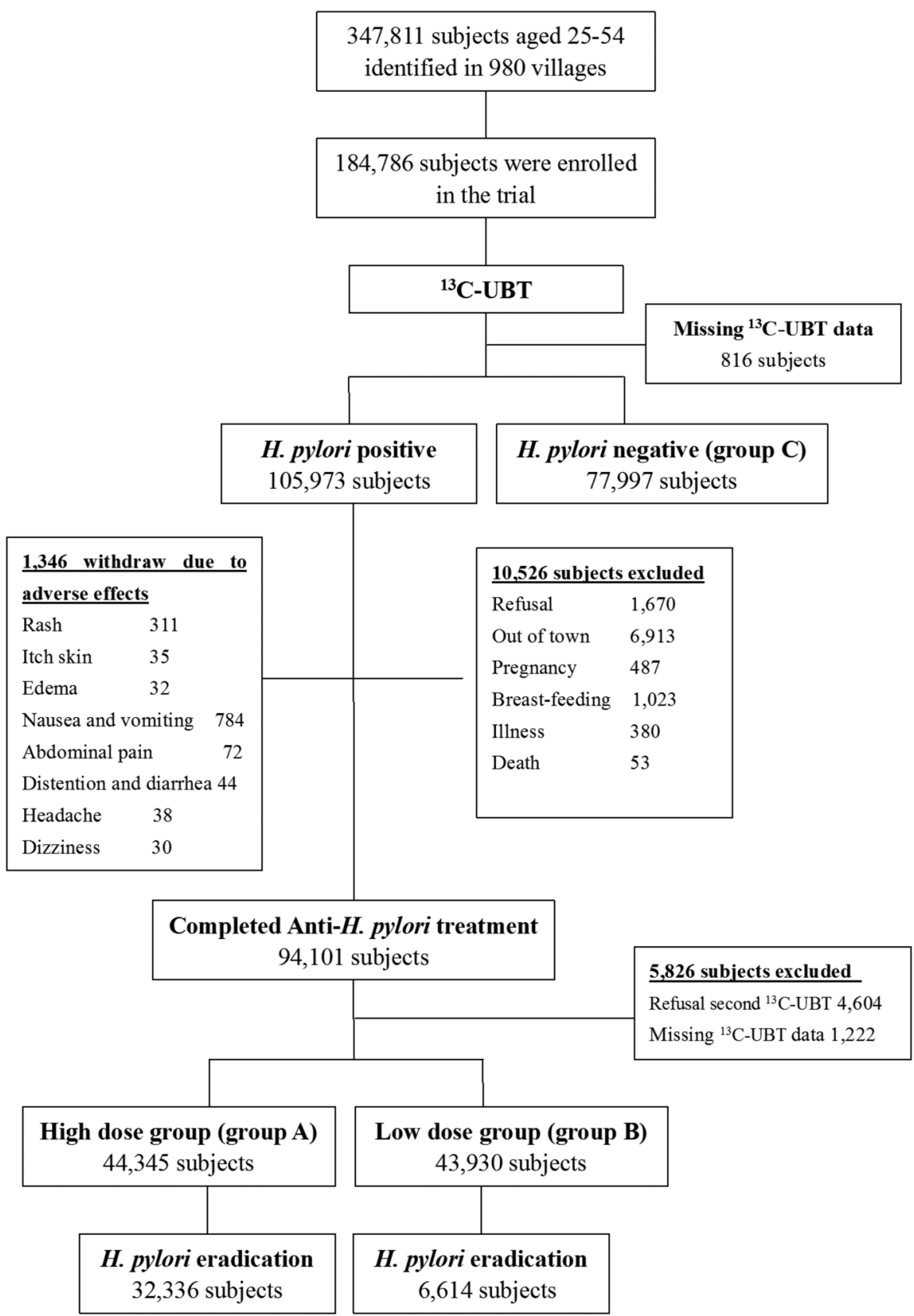

the compliance. Information on adverse events was collected and recorded on the adverse event case report form. All subjects with 10-day treatment underwent a second ${ }^{13} \mathrm{C}$-urea breath test $\left({ }^{13} \mathrm{C}-\mathrm{UBT}\right)$ at 45 days after treatment to determine the efficacy of $H$. pylori eradication. However, ${ }^{13} \mathrm{C}$-UBT was not performed in those who had not complete anti-H. pylori treatment.

\section{Follow-up procedures and monitoring}

The trial participants will prospectively undergo a follow-up for at least 7 years after the treatment. A rapid reporting system has been established in the population-based Cancer Registry in Linqu designated by the Chinese government. ${ }^{18}$ All new cancer cases are officially required to report to the Cancer Registry through an internet-based reporting system and a standard reporting form. All information on the cancer diagnosis using ICD-10:C00-96 is linked with the data collection and management system of our trial. For quality control, each village chief and village doctor will be responsible to report all cancer cases to the township doctors each month. The staff of PUCI will collect all information on the cancer cases every 3 months from township doctors and link the data with the Cancer Registry in Linqu, and then visit the villages every 6 months to validate the GC diagnosis and monitor the surveillance of each cancer case in the trial. If necessary, the staff will visit the hospital where the $\mathrm{GC}$ is diagnosed to obtain the medical files.

\section{Safety related procedures}

Participants were informed with a written information sheet by village leaders and PUCI staff and asked to report any potential adverse experiences to the investigator any time during the study. In addition, participants were withdrawn from the study within $24 \mathrm{~h}$ of any episodes of ulcer, perforation, upper GI bleeding or any moderate or severe adverse events regardless of whether or not the event resulted from treatment. 
Any adverse event/concurrent illness experienced by a subject during any portion of the study was described in detail and fully evaluated by the investigator. Any pertinent information was recorded in the case report form. Any severe side effects were required to be reported to the independent Data and Safety Monitoring Board.

\section{End points and statistical analysis}

The primary end point of this trial is the incidence of GC. Secondary end points are GC mortality and other health effects related to $H$. pylori eradication. If we apply a significance level of $5 \%$ and a power of $90 \%$ to detect a conservative estimate of at least a $20 \%$ reduction of GC risk, we need 625 GC cases in total, 349 in the placebo group and 276 in the active group, according to the estimated incidence rates for each year by age for H. pylori positive individuals in Linqu. The trial will be terminated at any time during the follow-up period if the difference of GC incidence rate between two arms reaches a statistically significant level.

Pearson's $\chi^{2}$ test was used to examine the differences of $H$. pylori prevalence and $H$. pylori eradication rate in different sex, age, marriage, smoking and drinking statuses, and the differences of side effects between two groups. An unconditional logistic regression model was applied in the analysis of influence factors for $H$. pylori eradication by a backward selection with a statistical significance at 0.05 . To test the dose effect of smoking and drinking on the $H$. pylori eradication rate, smoking and drinking indexes were generated, where smoking index= number of cigarettes taken per day $\times$ years of smoking and drinking index $=$ dosage of alcohol consumption per week $(\mathrm{kg}) \times$ years of drinking, respectively. Trend test of linear relationship between body mass index (BMI), baseline DOB, frequency of missed doses, smoking index and drinking index with H. pylori eradication rate were evaluated by unconditional logistic regression analysis adjusting for other risk factors. Furthermore, joint effects were calculated in different combinations of risk factors by logistic regression analysis. All $\mathrm{p}$ values were two-sided, and $\mathrm{p}<0.05$ was considered statistically significant. All statistical analyses were carried out using Statistical Analysis System software (V.9.0; SAS Institute, Cary, North Carolina, USA).

\section{RESULTS}

The field work of this intervention trial was launched in March 2011 and completed in September 2013 (30 months). A total of 184786 residents aged 25-54 years from 980 villages were enrolled, accounting for $53.1 \%$ of the relevant population of 347811 in Linqu (figure 1). Apart from refusing participation and meeting exclusion criteria, many migrant farm workers who were absent from home contributed to $53.1 \%$ of enrolment of the entire population.

\section{Overall prevalence of $\boldsymbol{H}$. pylori in study population}

Among 184786 subjects enrolled in the trial, 183970 had ${ }^{13} \mathrm{C}$-UBT results, and 105973 were $H$. pylori positive (figure 1; see online supplementary table S2). The overall prevalence of H. pylori in the trial participants was $57.6 \%$, slightly higher in men than in women $(59.0 \%$ vs $56.4 \%, \mathrm{p}<0.0001)$. The agespecific prevalence of $H$. pylori was $59.5 \%$ at 25-29 years, similar among those at 30-34 years, 35-39 years and 40-44 years, but a little lower among those at 45-49 years and $50-54$ years $(57.0 \%$ and $54.3 \%)$. The prevalence of $H$. pylori was at a similar level in different townships.

\section{Adverse events}

In 1346 subjects reporting moderate side effects, anti-H. pylori treatment was stopped including $916(2.3 \%)$ in group A and $430(0.98 \%)$ in group B $(\mathrm{p}<0.0001)$. The proportions of rash $(0.43 \%$ vs $0.27 \%, p<0.0001)$, nausea and vomiting $(1.28 \%$ vs $0.49 \%, \mathrm{p}<0.0001$ ) were higher in group A than in group B (see online supplementary table S3). No severe side effects or lifethreatening events were observed among all the subjects with a 10-day treatment during the entire 30 -month trial period.

\section{Compliance and balance in different groups}

Among $105973 \mathrm{H}$. pylori positive subjects, 94101 completed the treatment (compliance 88.8\%), and 88275 (compliance 93.8\%) finally received the second ${ }^{13} \mathrm{C}-\mathrm{UBT}$ after treatment including 44345 in group A and 43930 in group B. A total of $11872(11.2 \%)$ subjects withdrew before or during a 10-day treatment in the 30 -month trial period due to pregnancy, breast feeding, illness, being out of town, death, refusal and side effects (figure 1 ).

The randomisation of the trial participants reached an adequate balance between three groups within strata defined by baseline characteristics of the subjects (table 1). The majority of the subjects were farmers $(78.5 \%, 79.0 \%$ and $78.1 \%$, respectively) with education of middle school or less $(96.1 \%, 97.8 \%$ and 96.3\%, respectively). Smoking and alcohol drinking were frequent among men but not in women. About $10.7 \%$ of participants had family history of cancer $(11.2 \%, 10.5 \%$ and $10.6 \%$, respectively), and about $33.5 \%$ of participants were overweight or obese (BMI $\geq 25$ ) (33.8\%, 34.3\% and 32.7\%, respectively).

\section{Efficacy of the $\boldsymbol{H}$. pylori treatment and factors affecting H. pylori eradication}

The overall $H$. pylori eradication rate was $72.9 \%$ in group A and $15.1 \%$ in group B. As shown in table 2, except for age and BMI level, the $H$. pylori eradication rate in group A varied by gender, education, marriage, occupation, family cancer history, stomach disease history, smoking and drinking status. Men, subjects with college education, unmarried subjects or widows, smokers and alcohol drinkers, and subjects with family cancer history or stomach disease had lower eradication rates.

We further evaluated the factors influencing the eradication in 43846 subjects (out of 44345 ) with the full data in group A, including 20878 men and 22968 women. Among them, 32268 subjects had successful eradication of $H$. pylori, and 11578 had treatment failure. As summarised in table 3, male gender, missed doses, smoking, drinking, history of stomach disease, high BMI, and high baseline DOB were significantly and independently associated with the eradication failure by stepwise multivariate logistic regression analysis. A grade-response association was found between failure rate and smoking index (OR: 1.23 to 1.56, $\mathrm{P}_{\text {trend }}<0.001$ ), drinking index (OR: 1.11 to 1.29 , $\mathrm{P}_{\text {trend }}<0.001$ ), baseline DOB (OR: 1.09 to $1.19, \mathrm{P}_{\text {trend }}<0.001$ ) or missed medication doses (OR: 1.32 to $2.15, \mathrm{P}_{\text {trend }}<0.001$ ). Further stratified analysis by sex showed that high baseline DOB and missed doses were important contributors in men and women. However, a grade-response relationship between failure rate and smoking or drinking indices was only found in men (all $\left.\mathrm{P}_{\text {trend }}<0.001\right)$, and a history of stomach disease (OR 1.23, 95\% CI 1.10 to 1.38$)$ and high BMI $\left(\mathrm{P}_{\text {trend }}<0.001\right)$ were the significant predictors in women.

We were also interested in assessing the joint effect of risk factors for failure of $H$. pylori eradication. The joint effect was more evident and stronger in subjects with combined multiple 
Table 1 Baseline characteristics of participants in the different groups *

\begin{tabular}{|c|c|c|c|}
\hline Characteristics & Group A $(n=44345)$ & Group B $(n=43930)$ & Group C ( $n=77$ 997) \\
\hline Age, years & $42.77 \pm 7.86$ & $42.87 \pm 7.87$ & $42.79 \pm 8.21$ \\
\hline \multicolumn{4}{|l|}{ Sex } \\
\hline Men & $21107(47.6)$ & $20790(47.3)$ & $34588(44.3)$ \\
\hline Women & $23238(52.4)$ & $23140(52.7)$ & $43409(55.7)$ \\
\hline \multicolumn{4}{|l|}{ Education } \\
\hline Primary school & $15469(34.9)$ & $16679(38.0)$ & $24232(37.0)$ \\
\hline Middle school & $27134(61.2)$ & $26274(59.8)$ & $46209(59.2)$ \\
\hline College & $1738(3.9)$ & $967(2.2)$ & $2908(3.7)$ \\
\hline Missing & $4(0.0)$ & $10(0.0)$ & $16(0.0)$ \\
\hline \multicolumn{4}{|l|}{ Marriage } \\
\hline Married & $43806(98.8)$ & 43441 (98.9) & $76715(98.4)$ \\
\hline Unmarried & $366(0.8)$ & $315(0.7)$ & $931(1.1)$ \\
\hline Widow & $169(0.4)$ & $164(0.4)$ & $335(0.4)$ \\
\hline Missing & $4(0.0)$ & $10(0.0)$ & $16(0.0)$ \\
\hline \multicolumn{4}{|l|}{ Occupation } \\
\hline Farmer & $34829(78.5)$ & $34694(79.0)$ & $60931(78.1)$ \\
\hline Worker & $8218(18.5)$ & $8808(20.1)$ & $14941(19.2)$ \\
\hline Other & $1294(2.9)$ & $418(1.0)$ & $2109(2.7)$ \\
\hline Missing & $4(0.0)$ & $10(0.0)$ & $16(0.0)$ \\
\hline Income (RMB) & $10699 \pm 6843$ & $10461 \pm 6983$ & $10638 \pm 6892$ \\
\hline \multicolumn{4}{|l|}{ Family history of cancer } \\
\hline Yes & $4979(11.2)$ & $4616(10.5)$ & 8249 (10.6) \\
\hline No & 39362 (88.8) & $39304(89.5)$ & $69732(89.4)$ \\
\hline Missing & $4(0.0)$ & $10(0.0)$ & $16(0.0)$ \\
\hline \multicolumn{4}{|l|}{ History of stomach disease } \\
\hline Yes & $3545(8.0)$ & $3423(7.8)$ & 8169 (10.5) \\
\hline No & $40796(92.0)$ & $40497(92.2)$ & $69812(89.5)$ \\
\hline Missing & $4(0.0)$ & $10(0.0)$ & $16(0.0)$ \\
\hline \multicolumn{4}{|l|}{ Smoking } \\
\hline \multicolumn{4}{|l|}{ Men } \\
\hline Yes & $7158(33.9)$ & $6886(33.1)$ & $11452(33.1)$ \\
\hline No & $13946(66.1)$ & $13896(66.8)$ & $23128(66.9)$ \\
\hline Missing & $3(0.0)$ & $8(0.0)$ & $8(0.0)$ \\
\hline \multicolumn{4}{|l|}{ Women } \\
\hline Yes & $14(0.1)$ & $18(0.1)$ & $42(0.1)$ \\
\hline No & $23223(99.9)$ & $23120(99.9)$ & $43359(99.9)$ \\
\hline Missing & $1(0.0)$ & $2(0.0)$ & $8(0.0)$ \\
\hline \multicolumn{4}{|l|}{ Total } \\
\hline Yes & $7172(16.2)$ & $6904(15.7)$ & $11494(14.7)$ \\
\hline No & $37169(83.8)$ & $37016(84.3)$ & $66487(85.2)$ \\
\hline Missing & $4(0.0)$ & $10(0.0)$ & $16(0.0)$ \\
\hline \multicolumn{4}{|l|}{ Drinking } \\
\hline \multicolumn{4}{|l|}{ Men } \\
\hline Yes & 8789 (41.6) & $8400(40.4)$ & $13890(40.2)$ \\
\hline No & $12315(58.3)$ & $12382(59.6)$ & $20690(59.8)$ \\
\hline Missing & $3(0.0)$ & $8(0.0)$ & $8(0.0)$ \\
\hline \multicolumn{4}{|l|}{ Women } \\
\hline Yes & $196(0.8)$ & $182(0.8)$ & $326(0.8)$ \\
\hline No & 23041 (99.2) & $22956(99.2)$ & $43075(99.2)$ \\
\hline Missing & $1(0.0)$ & $2(0.0)$ & $8(0.0)$ \\
\hline \multicolumn{4}{|l|}{ Total } \\
\hline Yes & $8985(20.3)$ & $8582(19.5)$ & $14216(18.2)$ \\
\hline No & $35356(79.7)$ & $35338(80.4)$ & $63765(81.8)$ \\
\hline Missing & $4(0.0)$ & $10(0.0)$ & $16(0.0)$ \\
\hline \multicolumn{4}{|l|}{$\mathrm{BMI}\left(\mathrm{kg} / \mathrm{m}^{2}\right)$} \\
\hline Low weight $(<18.5)$ & $97(0.2)$ & $116(0.3)$ & $233(0.3)$ \\
\hline Normal weight (18.5-24.9) & $29251(66.0)$ & $28732(65.4)$ & $52219(67.0)$ \\
\hline Overweight (25-29.9) & $13969(31.5)$ & $14027(31.9)$ & $23793(30.5)$ \\
\hline Obese $(\geq 30)$ & $1023(2.3)$ & $1051(2.4)$ & $1744(2.2)$ \\
\hline Missing & $5(0.0)$ & $4(0.0)$ & $8(0.0)$ \\
\hline
\end{tabular}

${ }^{*}$ Date are presented as means \pm SD or $\mathrm{n}(\%)$.

$\mathrm{BMI}$, body mass index; RMB, ren min bi. 
Table 2 Helicobacter pylori eradication rate in group A stratified by baseline characteristics*

\begin{tabular}{|c|c|c|}
\hline Characteristics & Group A $(n=32336)$ & p Valuet \\
\hline Total & 32 336/44 345 (72.9) & \\
\hline Sex & & $<0.0001$ \\
\hline Men & $14418(68.3)$ & \\
\hline Women & 17918 (77.1) & \\
\hline Age, years & & 0.8521 \\
\hline $25-29$ & $2640(69.4)$ & \\
\hline $30-34$ & 2401 (71.6) & \\
\hline $35-39$ & $4901(75.1)$ & \\
\hline $40-44$ & $7343(74.9)$ & \\
\hline $45-49$ & $7976(73.4)$ & \\
\hline $50-54$ & $7075(70.8)$ & \\
\hline Education & & $<0.0001$ \\
\hline Primary school & $11470(74.1)$ & \\
\hline Middle school & $19659(72.5)$ & \\
\hline College & $1204(69.3)$ & \\
\hline Missing & $3(75.0)$ & \\
\hline Marriage & & 0.0019 \\
\hline Married & $31980(73.0)$ & \\
\hline Unmarried & $237(64.8)$ & \\
\hline Widow & $116(68.6)$ & \\
\hline Missing & $3(75.0)$ & \\
\hline Occupation & & 0.0037 \\
\hline Farmer & $25517(73.3)$ & \\
\hline Worker & $5886(71.6)$ & \\
\hline Other & 930 (71.9) & \\
\hline Missing & $3(75.0)$ & \\
\hline Smoking and drinking & & $<0.0001$ \\
\hline Smoking only & $1366(65.6)$ & \\
\hline Drinking only & $2646(67.9)$ & \\
\hline Smoking and drinking & $3209(63.0)$ & \\
\hline Never & $25112(75.5)$ & \\
\hline Missing & $3(75.0)$ & \\
\hline Family history of cancer & & $<0.0001$ \\
\hline Yes & $3499(70.3)$ & \\
\hline No & $28834(73.3)$ & \\
\hline Missing & $3(75.0)$ & \\
\hline History of stomach disease & & $<0.0001$ \\
\hline Yes & $2472(69.7)$ & \\
\hline No & $29861(73.2)$ & \\
\hline Missing & $3(75.0)$ & \\
\hline BMI $\left(k g / m^{2}\right)$ & & 0.2687 \\
\hline Low weight $(<18.5)$ & $66(64.7)$ & \\
\hline Normal weight (18.5-24.9) & $21362(73.0)$ & \\
\hline Overweight (25-29.9) & $10160(72.7)$ & \\
\hline Obese $(\geq 30)$ & $748(73.1)$ & \\
\hline
\end{tabular}

risk factors (table 4). For men, $H$. pylori eradication failure rate was up to $48.8 \%$ in subjects with high baseline DOB, missed doses, smoking and drinking, with a 2.87 -fold (95\% CI 2.24 to 3.68) increased risk of eradication failure compared with reference group. However, for women, the risk of eradication failure was more pronounced in subjects with high baseline DOB, history of stomach disease and missed doses (OR 2.67, 95\% CI 1.61 to 4.42$)$.

\section{DISCUSSION}

In Linqu County, a high-risk area of GC in China, more than $50 \%$ of 347811 eligible population aged 25-54 years participated in this trial, indicating an excellent feasibility and acceptance. This largest trial so far provides the unique opportunity to clarify whether and how to implement strategies for preventing GC by eradication of $H$. pylori in a large community setting.

We are one of the first groups to study the effects of treatment of H. pylori on GC and its precursors. Our Shandong Intervention Trial and another $2 \times 2$ factorial designed, randomised controlled trial in Linqu indicated that $H$. pylori eradication is effective in preventing GC and progression of gastric lesions. $^{12} 141519$ However, the sample size in those trials was relatively small and insufficient for estimation of the overall benefits and possible adverse consequences in the community-based eradication scheme. With the large sample size of 184786 subjects in this trial, we will achieve more power to directly detect the impact on the incidence of GC. In addition, it permits evaluation of the impact of reduction of GC and early preventive treatment among young adults aged 25-34 years in the trial, because we found that $50 \%$ of children at 3 years to $85 \%$ at 10 years were infected with $H$. pylori in Linqu and gastritis is very common in young adults. ${ }^{8} 9$ Moreover, the longitudinal outcomes indicated that $H$. pylori infection primarily enhanced the transition from superficial gastritis to atrophy, indicating that the inhibition of progression of gastric lesions in young adults might be a critical strategy.

We evaluated earlier several schemes of $H$. pylori treatment, including a dual or triple eradication therapy in Linqu, yielding an unsatisfactory eradication rate (64-69\%). ${ }^{12}{ }^{20}$ However, two trials reported that a bismuth-based quadruple therapy eradicated H. pylori infection by $93 \%$ and $88 \%$, respectively. ${ }^{21} 22$ Another clinical trial using the same regimen in 7 days and 10 days also showed high rates of eradication of $H$. pylori ${ }^{23}$ To assess the efficacy of this 10-day quadruple therapy and its safety in Linqu population, we conducted a placebo-controlled pilot study with 277 subjects in one village before this large trial, and H. pylori eradication rates were $76.7 \%$ by intention-to-treat (ITT) analysis and $83.3 \%$ by per-protocol (PP) analysis. ${ }^{24}$ Our experiences showed that elimination of $72.9 \%$ of $H$. pylori in this community-based treatment has been relatively successful. Besides strict monitoring and good compliance of treatment, low resistance to tetracycline $\left(3.5 \%\right.$ in China) ${ }^{25}$ which has not been widely used for more than 20 years in China, may be beneficial in H. pylori management. Although a high rate of resistance to metronidazole was found in China and Asia, ${ }^{25} 26$ the combined resistance to tetracycline and metronidazole was only $5.32 \%$ in Linqu population (data not shown). Moreover, the cost of this regimen is much lower than triple therapy with omeprazole, amoxicillin and clarithromycin management.

In this large trial, we found $15.1 \%$ of the subjects in group B turned to be negative in ${ }^{13} \mathrm{C}$-UBT assessments at 45 days after the therapy. There are several possible explanations for this result. ${ }^{13} \mathrm{C}$-UBT may give some false negative results (up to $5 \%$ ), particularly for those with values only slightly above the diagnostic threshold of ${ }^{13} \mathrm{C}$-UBT (possibly caused low density of $H$. pylori in the gastric mucosa). In addition, bismuth or omeprazole might have an impact on the eradication of $H$. pylori. Indeed, several studies have shown that a single dosage of $20 \mathrm{mg}$ or $40 \mathrm{mg}$ omeprazole can achieve about a $10-50 \%$ H. pylori eradication rate, ${ }^{27} 28$ and bismuth salts are partially effective in suppressing and eradicating $H$. pylori as monotherapy (eradication rates ranging from $0 \%$ to $32 \%),{ }^{29}{ }^{30}$ although $H$. pylori recurrence 
Table 3 Multivariable logistic regression analysis on the influence factors for Helicobacter pylori eradication rate

\begin{tabular}{|c|c|c|c|c|c|c|}
\hline \multirow[b]{2}{*}{ Factors } & \multicolumn{2}{|l|}{ Overall } & \multicolumn{2}{|l|}{ Male } & \multicolumn{2}{|l|}{ Female } \\
\hline & Successful/failed & OR $(95 \% \mathrm{Cl})$ & Successful/failed & OR $(95 \% \mathrm{Cl})$ & Successful/failed & OR $(95 \% \mathrm{Cl})$ \\
\hline \multicolumn{7}{|l|}{ Gender } \\
\hline Female & $17877 / 5091$ & 1.00 & NA & NA & NA & NA \\
\hline Male & $14391 / 6487$ & $1.39(1.32-1.47)$ & NA & NA & NA & NA \\
\hline \multicolumn{7}{|l|}{ Missed doses } \\
\hline No & $30529 / 10479$ & 1.00 & $13530 / 5855$ & 1.00 & $16999 / 4624$ & 1.00 \\
\hline Yes & $1739 / 1099$ & 1.79 (1.65 to 1.94$)$ & $861 / 632$ & 1.68 (1.50 to 1.87$)$ & $878 / 467$ & 1.94 (1.73 to 2.18$)$ \\
\hline \multicolumn{7}{|l|}{ Smoking } \\
\hline No & $27697 / 9051$ & 1.00 & $9827 / 3967$ & 1.00 & $17870 / 5084$ & 1.00 \\
\hline Yes & $4568 / 2526$ & 1.28 (1.19 to 1.37$)$ & $4561 / 2520$ & 1.27 (1.18 to 1.35$)$ & $7 / 6$ & 3.32 (1.08 to 10.14$)$ \\
\hline \multicolumn{7}{|l|}{ Drinking } \\
\hline No & $26424 / 8552$ & 1.00 & $8700 / 3504$ & 1.00 & $17724 / 5048$ & 1.00 \\
\hline Yes & $5841 / 3025$ & 1.16 (1.08 to 1.23$)$ & $5688 / 2983$ & $1.17(1.10$ to 1.25$)$ & $153 / 42$ & $0.90(0.64$ to 1.29$)$ \\
\hline \multicolumn{7}{|c|}{ Stomach disease } \\
\hline No & 29 798/10 540 & 1.00 & $13250 / 5907$ & 1.00 & $16548 / 4633$ & 1.00 \\
\hline Yes & $2467 / 1037$ & 1.13 (1.05 to 1.22$)$ & $1138 / 580$ & 1.05 (0.95 to 1.17$)$ & $1329 / 457$ & 1.23 (1.10 to 1.38$)$ \\
\hline \multicolumn{7}{|l|}{ BMI group* } \\
\hline$<25.0$ & $21379 / 7650$ & 1.00 & $9783 / 4484$ & 1.00 & 11 596/3166 & 1.00 \\
\hline $25.0 \sim$ & $10139 / 3661$ & 1.03 (0.99 to 1.08 ) & $4472 / 1950$ & 0.96 (0.90 to 1.03$)$ & $5667 / 1711$ & 1.12 (1.05 to 1.20$)$ \\
\hline$\geq 30.0$ & $745 / 267$ & 1.19 (1.03 to 1.37$)$ & $133 / 53$ & 0.88 (0.63 to 1.21$)$ & $612 / 214$ & 1.33 (1.13 to 1.56$)$ \\
\hline \multicolumn{7}{|c|}{ Baseline DOB† } \\
\hline Q1 & $8160 / 2798$ & 1.00 & $4428 / 1832$ & 1.00 & $3732 / 966$ & 1.00 \\
\hline Q2 & $8016 / 2942$ & 1.09 (1.03 to 1.16$)$ & $4013 / 1832$ & $1.11(1.02$ to 1.20$)$ & $4003 / 1110$ & 1.07 (0.97 to 1.18$)$ \\
\hline Q3 & $8024 / 2931$ & 1.13 (1.07 to 1.20$)$ & $3420 / 1627$ & 1.16 (1.07 to 1.25$)$ & $4604 / 1304$ & 1.10 (1.00 to 1.21$)$ \\
\hline Q4 & $8068 / 2889$ & 1.19 (1.12 to 1.26$)$ & $2530 / 1185$ & 1.15 (1.05 to 1.26$)$ & $5538 / 1704$ & 1.21 (1.10 to 1.32 ) \\
\hline \multicolumn{7}{|c|}{ Frequency of missed doses $¥$} \\
\hline 0 & $30529 / 10479$ & 1.00 & $13530 / 5855$ & 1.00 & $16999 / 4624$ & 1.00 \\
\hline 1 & $255 / 106$ & 1.19 (0.94 to 1.49$)$ & $118 / 55$ & $1.03(0.75$ to 1.43$)$ & $137 / 51$ & $1.37(0.99$ to 1.90$)$ \\
\hline 2 & $196 / 87$ & $1.32(1.02$ to 1.70$)$ & $74 / 51$ & $1.62(1.13$ to 2.31$)$ & $122 / 36$ & $1.08(0.74$ to 1.57$)$ \\
\hline $3-5$ & $241 / 129$ & 1.62 (1.30 to 2.01$)$ & $106 / 60$ & 1.34 (0.97 to 1.84$)$ & $135 / 69$ & 1.91 (1.43 to 2.56$)$ \\
\hline $6-29$ & $258 / 165$ & 1.82 (1.49 to 2.22 ) & $129 / 76$ & 1.32 (0.99 to 1.76$)$ & $129 / 89$ & 2.47 (1.88 to 3.25 ) \\
\hline Unknown & $789 / 612$ & 2.15 (1.92 to 2.40$)$ & $434 / 390$ & 2.06 (1.79 to 2.37$)$ & $355 / 222$ & 2.29 (1.93 to 2.72 ) \\
\hline \multicolumn{7}{|c|}{ Smoking index§ } \\
\hline 0 & $27697 / 9051$ & 1.00 & $9827 / 3967$ & 1.00 & $17870 / 5084$ & 1.00 \\
\hline Q1 & $906 / 482$ & $1.23(1.08$ to 1.38$)$ & $901 / 481$ & $1.22(1.08$ to 1.38$)$ & $5 / 1$ & 0.79 (0.09 to 6.98$)$ \\
\hline Q2+Q3 & $1677 / 878$ & 1.22 (1.11 to 1.34$)$ & $1676 / 876$ & $1.21(1.10$ to 1.33$)$ & $1 / 2$ & 5.78 (0.51 to 64.87$)$ \\
\hline Q4 & $1031 / 686$ & 1.56 (1.40 to 1.74$)$ & $1030 / 684$ & 1.54 (1.37 to 1.72$)$ & $1 / 2$ & 8.26 (0.74 to 92.26$)$ \\
\hline \multicolumn{7}{|c|}{ Drinking indexף } \\
\hline 0 & $26424 / 8552$ & 1.00 & $8700 / 3504$ & 1.00 & $17724 / 5048$ & 1.00 \\
\hline Q1 & $1427 / 690$ & 1.11 (1.00 to 1.22$)$ & $1322 / 664$ & $1.14(1.02$ to 1.26$)$ & $105 / 26$ & 0.81 (0.52 to 1.26$)$ \\
\hline $\mathrm{Q} 2+\mathrm{Q} 3$ & $3024 / 1520$ & 1.12 (1.03 to 1.21$)$ & $2981 / 1505$ & 1.13 (1.04 to 1.22$)$ & $43 / 15$ & $1.17(0.64$ to 2.13$)$ \\
\hline Q4 & $1381 / 813$ & 1.29 (1.17 to 1.43$)$ & $1377 / 812$ & 1.30 (1.18 to 1.44$)$ & $4 / 1$ & $0.69(0.07$ to 6.62$)$ \\
\hline
\end{tabular}

${ }^{*}$ Adjusted for sex, age, missed doses, smoking, drinking, history of stomach disease and baseline $\mathrm{DOB}$. Trend test gained $\mathrm{P}_{\text {trend }}=0.026$ in the whole population, and $\mathrm{P}_{\text {trend }}=0.217$ and $P_{\text {trend }}<0.001$ in men and women, respectively.

†Adjusted for sex, age, missed doses, smoking, drinking, history of stomach disease and BMI. Trend test gained $P_{\text {trend }}<0.001$ in the whole population, and $P_{\text {trend }}<0.001$ and $P_{\text {trend }}<0.001$ in men and women, respectively. $Q$ : quartile, $P_{25}=11.20, P_{50}=18.60, P_{75}=29.28$.

$\ddagger$ Adjusted for sex, age, smoking, drinking, history of stomach disease, BMl and baseline DOB. Trend test gained $P_{\text {trend }}<0.001$ in the whole population, and $P_{\text {trend }}<0.001$ and $P_{\text {trend }}<0.001$ in men and women, respectively.

$\S$ Adjusted for sex, age, missed doses, drinking, history of stomach disease, BMI and baseline DOB. Trend test gained $\mathrm{P}_{\text {trend }}<0.001$ in the whole population, and $\mathrm{P}_{\text {trend }}<0.001$ and $P_{\text {trend }}=0.035$ in men and women, respectively. Q: quartile, $P_{25}=10, P_{50}=20, P_{75}=30$.

१Adjusted for sex, age, missed doses, smoking, history of stomach disease, BMI and baseline DOB. Trend test gained $P_{\text {trend }}<0.001$ in the whole population, and $P_{\text {trend }}<0.001$ and $P_{\text {trend }}=0.821$ in men and women, respectively. $Q$ : quartile, $P_{25}=312.0, P_{50}=702.0, P_{75}=1419.6$.

BMI, body mass index; DOB, delta over baseline-value.

appeared more frequently in those patients. Omeprazole reduces the stomach acid which can inhibit $H$. pylori urease and therefore might change $H$. pylori activity, representing a direct effect on $H$. pylori. Omeprazole has also been found to have a number of anti-inflammatory actions that are independent of their effects on gastric acid secretion. ${ }^{31}$ Bismuth may have an anti-H. pylori action by a number of mechanisms including inhibition of cell wall synthesis, cell membrane function and protein synthesis. ${ }^{32}$ In addition, bismuth has been suggested to decrease the development of $H$. pylori resistance to antibiotics. $^{32}$ In the future, it will be interesting to re-evaluate the status of those subjects who turned to negative in the low dose group as well as the possibility of $H$. pylori recurrence in the two treatment arms. 
Table 4 Joint effect analysis of the influence factors for Helicobacter pylori eradication rate

\begin{tabular}{|c|c|c|c|c|c|c|}
\hline DOB & Drinking & Smoking & Missed doses & $\begin{array}{l}\text { Success } \\
\mathbf{N}(\%)\end{array}$ & $\begin{array}{l}\text { Failure } \\
\mathrm{N}(\%)\end{array}$ & OR $(95 \% \mathrm{Cl})$ \\
\hline \multicolumn{7}{|c|}{ Male* } \\
\hline 0 & 0 & 0 & 0 & $2137(75.0)$ & $712(25.0)$ & 1.00 \\
\hline 1 & 1 & 0 & 0 & 1701 (69.1) & $762(30.9)$ & 1.34 (1.19 to 1.51$)$ \\
\hline 1 & 0 & 1 & 0 & $875(65.1)$ & 470 (34.9) & 1.62 (1.40 to 1.86$)$ \\
\hline 1 & 0 & 0 & 1 & $286(62.0)$ & $175(38.0)$ & 1.86 (1.51 to 2.29$)$ \\
\hline 0 & 1 & 1 & 0 & $982(66.0)$ & $505(34.0)$ & $1.53(1.34$ to 1.76$)$ \\
\hline 0 & 1 & 0 & 1 & $48(61.5)$ & $30(38.5)$ & 1.86 (1.17 to 2.96$)$ \\
\hline 0 & 0 & 1 & 1 & $23(53.5)$ & $20(46.5)$ & 2.65 (1.45 to 4.86$)$ \\
\hline 1 & 1 & 1 & 0 & $2000(64.1)$ & $1118(35.9)$ & 1.67 (1.50 to 1.87$)$ \\
\hline 1 & 0 & 1 & 1 & $67(58.3)$ & $48(41.7)$ & $2.19(1.50$ to 3.20$)$ \\
\hline 1 & 1 & 0 & 1 & $97(52.4)$ & $88(47.6)$ & 2.73 (2.02 to 3.69 ) \\
\hline 0 & 1 & 1 & 1 & $69(53.5)$ & $60(46.5)$ & 2.60 (1.82 to 3.72$)$ \\
\hline 1 & 1 & 1 & 1 & $146(51.2)$ & $139(48.8)$ & 2.87 (2.24 to 3.68$)$ \\
\hline DOB & HSD & BMI & Missed doses & & & \\
\hline \multicolumn{7}{|c|}{ Femalet } \\
\hline 0 & 0 & 0 & 0 & 1993 (80.4) & 486 (19.6) & 1.00 \\
\hline 1 & 1 & 0 & 0 & $662(75.1)$ & $220(24.9)$ & 1.37 (1.14 to 1.64$)$ \\
\hline 1 & 0 & 1 & 0 & $4353(77.4)$ & 1271 (22.6) & $1.20(1.07$ to 1.35$)$ \\
\hline 1 & 0 & 0 & 1 & $410(65.0)$ & $221(35.0)$ & 2.21 (1.83 to 2.68$)$ \\
\hline 0 & 1 & 1 & 0 & $106(82.8)$ & $22(17.2)$ & 0.86 (0.53 to 1.37$)$ \\
\hline 0 & 1 & 0 & 1 & $14(70.0)$ & $6(30.0)$ & 1.76 (0.67 to 4.60$)$ \\
\hline 0 & 0 & 1 & 1 & $64(70.3)$ & $27(29.7)$ & 1.73 (1.09 to 2.75$)$ \\
\hline 1 & 1 & 1 & 0 & $276(69.2)$ & $123(30.8)$ & 1.83 (1.45 to 2.32$)$ \\
\hline 1 & 0 & 1 & 1 & $215(62.1)$ & 131 (37.9) & 2.50 (1.97 to 3.18$)$ \\
\hline 1 & 1 & 0 & 1 & $40(60.6)$ & $26(39.4)$ & 2.67 (1.61 to 4.42$)$ \\
\hline 0 & 1 & 1 & 1 & $8(88.9)$ & $1(11.1)$ & 0.52 (0.06 to 4.16$)$ \\
\hline 1 & 1 & 1 & 1 & $20(64.5)$ & $11(35.5)$ & 2.26 (1.08 to 4.75$)$ \\
\hline
\end{tabular}

Studies demonstrated that the efficacy of $H$. pylori eradication depended upon a number of factors. Smoking can stimulate gastric acid secretion, decrease gastric blood flow and mucus secretion, and thus might reduce the delivery of antibiotics to gastric mucosa. ${ }^{33}$ Alcohol drinking can affect $H$. pylori eradication at different levels, such as gastric emptying and acid secretion. ${ }^{35}$ Our study showed that smoking and drinking habits were the most important contributors to the eradication failure in men, consistent with previous studies. ${ }^{33-35}$ We also found that the high baseline DOB, as a potential indicator for $H$. pylori growth in the stomach, was an important predictor for eradication failure, confirming the findings of former study. ${ }^{36} \mathrm{It}$ would be tempting to speculate that high $H$. pylori load was associated with eradication failure and more severe gastritis, therefore, those subjects might benefit from extended therapies (duration from 10 days to 14 days). In our study, we found a grade-response association between BMI level and eradication failure in women, providing new evidence and suggesting that extended therapies should be recommended for those with high BMI. Several studies showed that $H$. pylori eradication rates increased with the severity of inflammation and activity, and decreased with the severity of atrophy. ${ }^{37}$ Although we didn't conduct an endoscopic screening before enrolment, our previous endoscopic survey in Linqu showed that chronic atrophic gastritis was nearly universal in the adult population. ${ }^{8}$ In spite of a very good compliance of treatment, we identified that missed doses were an important predictor for eradication failure, particularly for women with more than three missed doses, indicating that patients require detailed information. In addition, we found that missed doses were more common among those with college education due to busy daily work (4.00\% vs $2.75 \%$ among those with primary school education, $\mathrm{p}=0.005)$, corresponding with a lower eradication rate $(69.3 \%)$ in those subjects. Together, the results indicate that more attention should be paid to environmental and patient-specific factors to increase the successful eradication of $H$. pylori and thus improve prevention and control of GC development.

The prevalence of $H$. pylori declined from $67.1 \%$ in 1995 , to $63.2 \%$ in 2002 and $57.6 \%$ in 2011/2013 among the residents in Linqu, consistent with the consensus of the second Asia-Pacific conference of $H$. pylori management, which states that a decline in prevalence of $H$. pylori appears to parallel economic improvement within a particular country. ${ }^{38}$ The infection of $H$. pylori is acquired at very young age of 3 years and is highly associated with parental, particularly maternal infection, suggesting person-to-person transmission is the most plausible route of $H$. pylori infection in Linqu. ${ }^{39}$ Moreover, drinking shallow water is associated with $H$. pylori infection. ${ }^{40}$ The sanitation system improved in the past 18 years, which may account for the annual reduction of $0.54 \%$ prevalence in this region. However, a higher prevalence of $H$. pylori infection in patients who developed GC was found in our previous cohort study in Linqu $(76.5 \%$ in the GC group vs $54.8 \%$ in the superficial gastritis group), ${ }^{10} 41$ and the crude mortality rate of GC in Linqu 
has not significantly declined over the past decades. Beside $H$. pylori, our series of epidemiological studies in Linqu suggested that dietary and other environmental risk factors as well as interaction with $H$. pylori infection may also play important roles in GC development. ${ }^{11} 42$

$H$. pylori eradication might be associated with the development of gastro-oesophageal disease and esophageal adenocarcinoma. A negative association between the prevalence of $H$. pylori and the severity of GORD has been demonstrated in epidemiological studies. ${ }^{43}$ However, several cohort studies and randomised controlled trials of the effects of $H$. pylori eradication on GORD are inconclusive. ${ }^{43}{ }^{44} \mathrm{~A}$ recent meta-analysis demonstrated that eradication of $H$. pylori was related to the higher risk of developing GORD in Asian studies. ${ }^{44}$ In contrast, no such risk has been reported by Western studies. ${ }^{45}$ However, two recent large-scale cohort studies in Korea produced inconsistent results. ${ }^{46} 47$ In addition, our previous endoscopic surveys revealed that GORD was rare and oesophageal adenocarcinoma was uncommon in Linqu, ${ }^{48}$ therefore, the risk of increasing GORD and oesophageal adenocarcinoma may be minor in comparison with the benefits of a $20-40 \%$ of reduction in GC incidence in Linqu.

Our large-scale trial has several strengths compared with previous trials. First, it is a prospective, randomised, placebocontrolled trial with good quality control in a well-organised high-risk population. The large sample size could increase the power and the possibility of observation strata. Second, the high treatment compliance might enhance the reliability of the trial, and using a data collection and management system could avoid errors occurring during the data collection and management processes. In addition, an excellent balance of variables in the three groups indicated a high quality implementation of this large trial.

This large-scale trial has also several potential limitations. One of the limitations is that the low dose group is not a pure placebo group due to ethical considerations, and participants assigned to the low dose regimen are expected to suffer from the disadvantage of developing more GCs. However, efforts were made to obtain maximal benefits for each trial participant. During the follow-up period, participants are eligible to receive any medical care including anti- $H$. pylori treatment. They also have a right and an equal chance to participate in the endoscopy screening program for early detection of GC, which is free of charge and designed by the Chinese Ministry of Health in an endoscopy centre of Linqu County Hospital each year. In the mean time, participants will be closely followed by PUCI staff and township/village doctors, who are responsible for local medical care. They will contact the participants closely to discover any symptoms of gastric diseases every 3 months and decide/suggest if the participant needs to receive the treatment or requires further examination in Linqu County Hospital. We will systematically collect the medical care information of participants through the medical insurance, and adjust the effect of treatment by stratified analysis at the end of the trial. If this unique trial reveals a beneficial effect on GC risk by eradication of $H$. pylori, we will provide treatment to the subjects in the low dose arm at the end of the trial period. Second, the cluster randomisation design could reach a slightly lower efficacy than the individual randomisation. However, it is difficult, if not impossible, to randomise each individual in such a large sample size trial.

In conclusion, to prevent the burden of one million new GC cases each year in the world, we initiated a large-scale intervention trial, representing more than $50 \%$ of adults aged $25-54$ years in 980 villages in Linqu. This important trial will finally answer many remaining questions and evaluate the cost-benefit in GC prevention strategy. Importantly, we identified and confirmed several risk factors affecting eradication, helping to improve the personalised efficacy of the therapy in the future, particularly in a community-based treatment.

\section{Author affiliations}

${ }^{1}$ Key Laboratory of Carcinogenesis and Translational Research (Ministry of

Education), Department of Cancer Epidemiology, Peking University Cancer Hospital

\& Institute, Beijing, China

${ }^{2}$ Technische Universität München, Munich, Germany

${ }^{3}$ Healthy Bureau of Linqu County, Weifang, China

${ }^{4}$ Institute of Pathology, Klinikum Bayreuth, Bayreuth, Germany

${ }^{5}$ Department of Medicine, 1st Faculty of Medicine, Military University Hospital,

Charles University, Prague, Czech Republic

${ }^{6}$ International Digestive Cancer Alliance, Germany

Acknowledgements The authors thank the trial participants, field staff and government of Linqu for supporting this large trial, the Wei-fang Centre for Disease Control (CDC) for their support in biospecimen storage collected in this trial, and the Beijing Double-Crane Pharmaceutical for donation of the bismuth-based quadruple medicines and its placebo in the trial. The authors also thank members of the Scientific Committee Drs G Tytgat (Chairmen), SD Xiao, JE Geenen, P Malfertheiner, F Bazzoli, D Forman and ZW Dong, and the Data Safety Monitoring Committee Drs $\mathrm{KC} \mathrm{Wu}, \mathrm{YH} \mathrm{Hu}, \mathrm{F}$ Megraud and WJ Blot for guidance and overseeing of this trial. In addition, the authors thank Dr Ruanren Hu for consultation of the trial randomisation.

Contributors All authors directly participated in the planning, execution or analysis of the study. All authors have read and approved the final version submitted. All authors accept responsibility for its content. Study organisation was by $W-c Y$ and $M C$, and $W-c Y$ designed the study. W-CY, MC, K-fP, Lian Z, RS, MG, MB, MV, MQ and SS supervised the execution of the study. J-IM, W-dL, J-xW, Lei Z, L-fZ, ML, $\mathrm{R}-\mathrm{yL}, \mathrm{L}-\mathrm{hW}, \mathrm{TZ}$ and $\mathrm{W}-\mathrm{xG}$ were responsible for the field administration and data collection. K-fP, KU and Lei Z performed the statistical analyses. W-cY, MC, K-fP, RS and MG drafted the manuscript.

Funding This research was supported in part by grants from Key International S\&T Cooperation Project (2010DFB30310), National Basic Research Program of China (973 program 2010CB529303), a grant from Peking University Cancer Hospital \& Institute, China, and International Office BMBF (CHN 11/021), DZIF German Centre for Infection Research, München, Germany.

Competing interests None declared.

Patient consent Obtained.

Ethics approval The project was approved by the Institutional Review Board of $\mathrm{PUCl}$ and collaborating institutions.

Provenance and peer review Not commissioned; externally peer reviewed.

\section{REFERENCES}

1 Huang JQ, Sridhar S, Hunt RH. Role of Helicobacter pylori infection and non-steroidal antiinflammatory drugs in peptic-ulcer disease: a meta-analysis. Lancet 2002;359:14-22.

2 Helicobacter and Cancer Collaborative Group. Gastric cancer and Helicobacter pylori: a combined analysis of 12 case control studies nested within prospective cohorts. Gut 2001:49:347-53.

3 Correa P, Miller MJ. Carcinogenesis, apoptosis and cell proliferation. Br Med Bull 1998;54:151-62

4 Cancer Genome Atlas Research Network. Comprehensive molecular characterization of gastric adenocarcinoma. Nature 2014;513:202-9.

5 Correa P. Human gastric carcinogenesis: a multistep and multifactorial processFirst American Cancer Society Award Lecture on Cancer Epidemiology and Prevention. Cancer Res 1992;52:6735-40.

6 [No authors listed]. Schistosomes, liver flukes and Helicobacter pylori. IARC Working Group on the Evaluation of Carcinogenic Risks to Humans. Lyon, 7-14 June 1994. IARC Monogr Eval Carcinog Risks Hum 1994;61:1-241.

7 Malfertheiner P, Sipponen P, Naumann M, et al. Helicobacter pylori eradication has the potential to prevent gastric cancer: a state-of-the-art critique. $\mathrm{Am} \mathrm{J}$ Gastroenterol 2005;100:2100-15.

8 You WC, Blot WJ, Li JY, et al. Precancerous gastric lesions in a population at high risk of stomach cancer. Cancer Res 1993;53:1317-21.

9 You WC, Zhang L, Pan KF, et al. Helicobacter pylori Prevalence and CagA status among children in two counties of China with high and low risks of gastric cancer. Ann Epidemiol 2001;11:543-6.

10 Zhang L, Blot WJ, You WC, et al. Helicobacter pylori antibodies in relation to precancerous gastric lesions in a high-risk Chinese population. Cancer Epidemiol Biomarkers Prev 1996;5:627-30. 
11 You WC, Zhang L, Gail MH, et al. Gastric dysplasia and gastric cancer: Helicobacter pylori, serum vitamin C, and other risk factors. J Nat/ Cancer Inst 2000;92:1607-12.

12 You WC, Brown LM, Zhang L, et al. Randomized double-blind factorial trial of three treatments to reduce the prevalence of precancerous gastric lesions. J Nat/ Cancer Inst 2006;98:974-83.

13 Gail MH, You WC, Chang YS, et al. Factorial trial of three interventions to reduce the progression of precancerous gastric lesions in Shandong, China: design issues and initial data. Control Clin Trials 1998;19:352-69.

14 Ma JL, Zhang L, Brown LM, et al. Fifteen-year effects of Helicobacter pylori, garlic, and vitamin treatments on gastric cancer incidence and mortality. J Nat/ Cancer Inst 2012;104:488-92.

15 Li WQ, Ma JL, Zhang L, et al. Effects of Helicobacter pylori treatment on gastric cancer incidence and mortality in subgroups. J Natl Cancer Inst 2014;106. pii: dju116.

16 Ford AC, Forman D, Hunt RH, et al. Helicobacter pylori eradication therapy to prevent gastric cancer in healthy asymptomatic infected individuals: systematic review and meta-analysis of randomized controlled trials. BMJ 2014;348:g3174.

17 Helicobacter pylori eradication as a strategy for preventing gastric cancer. IARC working group reports. Volume 8. http://www.iarc.fr/en/publications/pdfs-online/wrk/ wrk8/index.php

18 He J, Chen WQ. Chinese cancer registry annual report 2012. National Cancer Center, Disease Prevention and Control Bureau, Ministry of Health. 2012.

19 Wong BC, Zhang L, Ma JL, et al. Effects of selective COX-2 inhibitor and Helicobacter pylori eradication on precancerous gastric lesions. Gut 2012;61:812-18.

20 Zhang $L$, Shen L, Ma JL, et al. Eradication of $H$ pylori infection in a rural population: one-day quadruple therapy versus 7-day triple therapy. World J Gastroenterol 2006;12:3915-18.

21 O'Morain C, Borody T, Farley A, et al. Efficacy and safety of single-triple capsules of bismuth biskalcitrate, metronidazole and tetracycline, given with omeprazole, for the eradication of Helicobacter pylori: an international multicentre study. Aliment Pharmacol Ther 2003;17:415-20.

22 Laine L, Hunt R, El-Zimaity $\mathrm{H}$, et al. Bismuthbased quadruple therapy using a single capsule of bismuth biskalcitrate, metronidazole, and tetracycline given with omeprazole versus omeprazole, amoxicillin, and clarithromycin for eradication of Helicobacter pylori in duodenal ulcer patients: a prospective, randomized, multicenter, North American trial. Am J Gastroenterol 2003;98:562-7.

23 Zheng Q, Dai J, Li X, et al. Comparison of the efficacy of pantoprazole-based triple therapy versus quadruple therapy in the treatment of Helicobacter pylori infection. Chines J Gastroenterol 2009;14:38-40.

24 Ma J, Liu W, Zhang L, et al. A placebo-controlled trial of 10-day bismuth-based quadruple therapy to eradicate Helicobacter pylori infection; a pilot study for the large Linqu County trial. Eur J Gastroenterol Hepatol 2010;22:597-601.

25 Song Z, Zhang J, He L, et al. Prospective multi-region study on primary antibiotic resistance of Helicobacter pylori strains isolated from Chinese patients. Dig Liver Dis 2014;46:1077-81.

26 De Francesco V, Giorgio F, Hassan C, et al. Worldwide $H$. pylori antibiotic resistance: a systematic review. J Gastrointestin Liver Dis 2010;19:409-14.

27 El-Nakeeb A, Fikry A, Abd El-Hamed TM, et al. Effect of Helicobacter pylori eradication on ulcer recurrence after simple closure of perforated duodenal ulcer. Int J Surg 2009;7:126-9.

$28 \mathrm{Ng} \mathrm{EK}$, Lam YH, Sung JJ, et al. Eradication of Helicobacter pylori prevents recurrence of ulcer after simple closure of duodenal ulcer perforation: randomized controlled trial. Ann Surg 2000;231:153-8.
29 Marshall BJ, Valenzuela JE, McCallum RW, et al. Bismuth subsaliculate suppression of Helicobacter pylori in nonulcer dyspepsia: a double blind placebo-controlled trial. Dig Dis Sci 1993;38:1674-80.

30 Bardhan KD, Dallaire C, Eisold $H$, et al. The treatment of duodenal ulcer with GR 122311X (ranitidine bismuth citrate) and clarithromycin. Gut 1995;37(Suppl. 1):A5.

31 Huo $X$, Zhang $X, Y u$, et al. In oesophageal squamous cells exposed to acidic bile salt medium, omeprazole inhibits IL-8 expression through effects on nuclear factor- $\kappa B$ and activator protein-1. Gut 2014;63:1042-52.

32 Lambert JR, Midolo P. The actions of bismuth in the treatment of Helicobacter pylori infection. Aliment Pharmacol Ther 1997;11:27-33.

33 Namiot DB, Leszczyńska K, Namiot Z, et al. Smoking and drinking habits are important predictors of Helicobacter pylori eradication. Adv Med Sci 2008:53:310-15

34 Suzuki T, Matsuo $\mathrm{K}$, Ito $\mathrm{H}$, et al. Smoking increases the treatment failure for Helicobacter pylori eradication. Am J Med. 2006;119:217-24.

35 Queiroz DM, Dani R, Silva LD, et al. Factors associated with treatment failure of Helicobacter pylori infection in a developing country. J Clin Gastroenterol. 2002;35:315-20.

36 Perri F, Villani MR, Festa V, et al. Predictors of failure of Helicobacter pylori eradication with the standard 'Maastricht triple therapy'. Aliment Pharmacol Ther. 2001;15:1023-9.

37 Kamada T, Haruma K, Komoto K, et al. Effect of smoking and histological gastritis severity on the rate of $H$. pylori eradication with omeprazole, amoxicillin, and clarithromycin. Helicobacter 1999;4:204-10.

38 Fock KM, Katelaris P, Sugano K, et al. Second Asia-Pacific Consensus Guidelines for Helicobacter pylori infection. J Gastroenterol Hepatol 2009;24:1587-600.

39 Ma JL, You WC, Gail MH, et al. Helicobacter pylori infection and mode of transmission in a population at high risk of stomach cancer. Int J Epidemiol 1998;27:570-3

40 Brown LM, Thomas TL, Ma JL, et al. Helicobacter pylori infection in rural China: demographic, lifestyle and environmental factors. Int J Epidemiol 2002;31:638-45.

41 Li ZX, Wang YM, tang FB, et al. NOD1 and NOD2 genetic variants in association with risk of gastric cancer and its precursors in a chinese population. PLOS ONE 2015; 10:e0124949.

42 Liu F, Pan K, Zhang X, et al. Genetic variants in cyclooxygenase-2: expression and risk of gastric cancer and its precursors in a Chinese population. Gastroenterology 2006;130:1975-84.

43 Hong SJ, Kim SW. Helicobacter pylori Infection in Gastroesophageal Reflux Disease in the Asian Countries. Gastroenterol Res Pract 2015;2015:985249.

44 Xie T, Cui X, Zheng H, et al. Meta-analysis: eradication of Helicobacter pylori infection is associated with the development of endoscopic gastroesophageal reflux disease. Eur J Gastroenterol Hepatol 2013;25:1195-205.

45 Saad AM, Choudhary A, Bechtold ML. Effect of Helicobacter pylori treatment on gastroesophageal reflux disease (GERD): meta-analysis of randomized controlled trials. Scand J Gastroenterol. 2012;47:129-35.

46 Nam SY, Choi IJ, Ryu KH, et al. Effect of Helicobacter pylori infection and its eradication on reflux esophagitis and reflux symptoms. Am J Gastroenterol. 2010;105:2153-62.

47 Kim N, Lee SW, Kim Jl, et al. Effect of Helicobacter pylori Eradication on the Development of Reflux Esophagitis and Gastroesophageal RefluxSymptoms: A Nationwide Multi-Center Prospective Study. Gut Liver 2011;5:437-46.

48 Lü YL, Li Y, Liu GS, et al. Comparison of two gastric cancer screening schemes in a high-risk population. Zhonghua Zhong Liu Za Zhi 2013;35:394-7. 